\title{
Sistem Informasi Geografis (SIG) Pemetaan Kost-Kosan Menggunakan Metode Formula Haversine
}

\author{
Muhammad Ibnu Sa'ad, Muhammad Surahmanto, Muhammad Rizki Pratono Soemari, \\ Kusrini, M. Syukri Mustafa \\ S2 Teknik Infromatika, Universitas AMIKOM Yogyakarta \\ STMIK Dipanegara Makassar \\ Universitas Muhammadiyah Sorong \\ FKIP Universitas Mulawarman, SD Muhammadiyah 1 Samarinda \\ Pascasarjana Amikom Yogyakarta, Kecamatan. Depok, Kabupaten Sleman, Daerah Istimewa \\ Yogyakarta 55281, (0274) 884201 - 207 \\ ibnusaad336@gmail.com,surahmanto@um-sorong.ac.id, rizkipratono@yahoo.com, \\ kusrini@amikom.ac.id,syukri@dipanegara.ac.id
}

\begin{abstract}
Geographic Information System ia a geospatial software system that has the ability to build, store, manage and display geo-referenced information, for example data that is identified by location. By using GIS, it is expected that it will be easier for prospective students and students to find out the location of boarding houses that are located around the campus of Mulawarman University. The system development method uses the waterfall method. While the system design method uses UML (Unified Modelling Language) to visualize, determine, develop and document a software system. The algorithm used in this study uses the haversine formula which will later help to find the nearest boarding house location around the campus of Mulawarman University, the haversine formula will produce the shortest distance between two points, for example on a ball taken from the longitude and latitude. The result of this study will disply detailed boarding location information, besides that on this geograpihic information system the user will later be able to see the details of boarding and admin data can change, add data to the boarding owner and be technically responsible for the running of the application, while the boarding owner is only responsible on managing boarding data on their respective users.
\end{abstract}

Keywords: Geographic Information System, Formula Haversine

\section{Abstrak}

Sistem Informasi Geografis merupakan sistem perangkat lunak geospasial yang memiliki kemampuan untuk mambangun, menyimpan, mengelola dan menampilkan informasi bereferensi geografis. Dengan menggunakan SIG diharapkan lebih mudah bagi para calon mahasiswa maupun mahasiswa untuk mengetahui pemetaan lokasi kost-kosan yang berada disekitaran kampus Universitas Mulawarman. Metode pengembangan sistem menggunakan metode waterfall, pada tahapannya menganalisa data, merancang sistem, implementasi dan integrasi. Sedangkan metode perancangan sistemnya menggunakan UML untuk memvisualisasikan, menentukan, membangan dan mendokumentasikan sebuah sistem perangkat lunak. Algoritma yang digunakan pada penelitian ini menggunakan Formula Haversine yang membantu untuk mencari lokasi kos-kosan terdekat disekitaran kampus universitas mulawarman, formula haversine menghasilkan jarak terpendek antara dua titik, misalnya pada bola yang diambil dari garis bujur (longitude) dan garis lintang (latitude). Hasil penelitian ini menampilkan informasi detail lokasi kost-kosan, melihat detail data kost dan admin dapat mengubah, menambah data pemilik kost serta bertanggungjawab secara teknis terhadap jalannya aplikasi, sedangkan pemilik kost hanya bertanggungjawab terhadap pengelolaan data kost pada user mereka masing-masing.

Kata kunci: Sistem Informasi Geografis, Formula Haversine 


\section{PENDAHULUAN}

Sistem Informasi Geografis (SIG) atau Geographic Information System (GIS) adalah suatu sistem basis data yang mempunyai kemampuan untuk menangani data bereferensi spasial yang bersamaan dengan seperangkat operasi kerja [1]. Menurut Anon dalam Sastrohartono, Sistem Informasi Geografis adalah sistem informasi yang bisa dipadukan antara data grafis dan data teks yang kemudian dihubungkan secara geografis di bumi (georeference). Sistem Informasi Geografis saat ini telah berkembang dengan sangat cepat, sehingga pengecekan lokasi dari maps akan bisa lebih memenuhi kebutuhan masyarakat. Pendampingan yang akan bisa dilakukan untuk bisa menerima perkembangan teknologi ini diharapkan bisa menjadikan partisipasi masyarakat bisa berkembang dan mengubah perilaku masyarakat pada umumnya. Teknologi Informasi dan Komputer (TIK) merupakan hal yang mendasar untuk bisa diketahui oleh semua pihak, hal ini bisa diciptakan sebuah kawasan yang bisa muncul untuk bisa dikembangkan ke masyarakat lebih luas.

Sistem Informasi Geografis merupakan sistem perangkat lunak geospasial yang secara umumnya memiliki kemampuan untuk mambangun, menyimpan, mengelola dan menampilkan informasi geografis, misalnya data yang telah diidentifikasi menurut titik lokasinya. dalam sebuah database, sistem informasi geografis dapat membantu dalam perencanaan, pengawasan dan pembuatan keputusan dengan memadukan antara data spasial dan non-spasial [2]. Pada dasarnya, sistem informasi geografis adalah suatu sistem terdiri dari komponen-komponen yang saling berkaitan (berhubungan) dalam mencapai suatu sasaran, berdasarkan informasi (data, fakta, kondisi, fenomena) berbasis geografis (daerah, spasial, keruangan) yang dapat dicek posisinya di permukaan bumi (bergeoferensi). Kedua jenis data, baik spasial maupun tubular/tekstual disimpan dalam suatu sistem yang dikenal dengan basis data SIG [3]. Sistem basis data ini merupakan komponen utama yang harus tersedia dalam SIG, disamping komponen lain seperti sistem komputer, sumber daya manusia dan organisasi atau wadah pengelolaan yang mengendalikan penggunaan SIG [4]. GIS memiliki berapa komponen yaitu komputer, data geospasial, dan pengguna [5]. SIG mengolah 2 macam data yaitu data geospasial atau yang biasanya disebut data spasial dan data nonspasial (atribut).

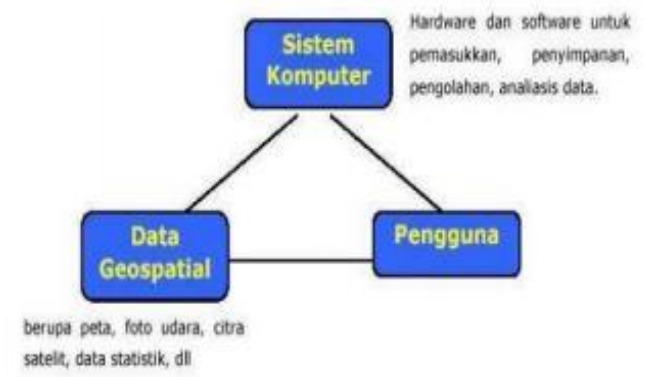

Gambar 1. Komponen GIS 
Pada penelitian sebelumnya, penelitian pertama oleh Sunil Pratap Singh and Preetvanti Singh International Journal of Database Management System [6] dalam penelitiannya "Modeling A Geo-Spatial Database For Managing Traveler's Demand". Dalam penelitian tersebut, peneliti melakukukan penelitian merancang dan mengimplementasikan database geo-spasial untuk mengelola permintaan pelancong dengan bantuan alat sumber terbuka dan paket basis data objek-relasional. Pembangunan basis data geo-spasial dimulai dengan perancangan model data dalam hal konseptual, logis dan model data fisik dan kemudian desain telah diimplementasikan ke dalam database objek-relasional. basis data geo-spasial dikembangkan untuk memfasilitasi penyimpanan informasi geografis dengan informasi deskriptif ke dalam model vector. Basis data geo-spasial, yang dikembangkan dalam penelitian ini merupakan sumber yang bagus untuk menggambarkan dan mengidentifikasi elemen infrastruktur yang terkait dengan permintaan wisatawan secara geometris, tematis, dan secara topologis.

Penelitian kedua oleh ZHAO Chun-yu, ZHAO Yuan-chun, MENG Ling-kui, DENG Shi-jun [7] Dalam Penelitiannya "The Key Technologic Issues of Parallel Spatial Database Management System For Parallel GIS". Dalam penelitian tersebut menyajikan kerangka kerja perangkat lunak baru dari manajemen data spasial dalam GIS berdasarkan pada sistem manajemen database spasial paralel (PSDBMS) untuk memecahkan kesulitan dalam menyimpan dan mengambil data spasial volume besar. Aplikasi ini melibatkan penambangan data spasial dan penemuan pengetahuan, GIS multi-dimensi dan dinamis, GIS spasial-temporal.

Penelitian ketiga oleh H. A. Umar , M. F. Abdul Khanan ,* A. Ahmad M. J. Sani , M.Z. Abd. Rahman, A. Abdul Rahman [8] Dalam Penelitiannya "Spatial Database Development For Oil Spills Pollution Affecting Water Quality System in Niger Delta". Dalam penelitiannya menganalisisi geospasial yang digunakan untuk mendesain basis data tumpahan minyak yang terdiri dari desain basis data logis, fisik, dan konseptual. kertas adalah untuk mengembangkan database tentang bagaimana tumpahan minyak mempengaruhi kualitas air yang merupakan salah satu sumber daya paling penting di Delta Niger. Analisis geospasial digunakan untuk mendesain basis data tumpahan minyak yang terdiri dari desain basis data logis, fisik, dan konseptual. Visio digunakan untuk desain diagram entitas relationship (ER) dari penelitian ini. Hasil distribusi tumpahan spasial dari kepadatan Kernel dan statistik Getis-Ord G* mengungkapkan bahwa tiga negara dari Delta Niger yaitu, Bayelsa, Rivers, dan negara-negara Delta adalah tempat terpanas untuk kejadian dan distribusi tumpahan minyak.

Penelitian keempat oleh Sugiarto, Ertien Rining Nawangsari [9] Dalam Penelitiannya "Data Spatial Pada Pembuatan Peta Tematik Dengan API Maps Google". Dalam penelitiannya tersebut tentang dapat spasial yang merupakan langkah awal untuk bisa membuat sebuah solusi pemetaan yang statis, Dari model peta statis ini diharapkan bisa dikembangkan dengan model dinamis agar masyarakat bisa menerima perkembangan teknologi ini 
diharapkan bisa menjadikan partisipasi masyarakat bisa berkembang dan mengubah perilaku masyarakat pada umumnya. Melalui pendekatan partisipatif ini masyarakat dapat memiliki pengaruh dan kontrol terhadap berbagai inisiatif pembangunan dan pemanfaatan sumber daya yang akan mempengaruhi kehidupannya maupun lingkungannya, Masyarakat mempunyai informasi yag variatif sehingga dari model variatif ini bisa dijadikan untuk bahan pengumpulan data spatial yang akan disusun menjadi sebuah database sebuah sistem.

Kampus Universitas Mulawarman yang teletak di Provinsi Kalimantan Timur merupakan perguruan Tinggi terbesar yang berada di kota Samarinda Provinsi Kalimantan Timur, banyaknya mahasiswa dari luar kota atau perantau yang menuntut ilmu di kampus tersebut. berkaitan dengan hal tersebut, permasalahan yang sering dihadapi oleh mahasiswa perantau ialah mencari tempat kos-kosan yang jaraknya dekat dengan kampus Universitas Mulawarman atau disekitaran kampus tersebut dan juga memiliki fasilitas yang cocok dan sesuai dengan harga yang telah di tentukan oleh pemilik koskosan. Sistem Informasi Geografis menggunakan metode formula haversine ini nantinya akan membantu untuk mencari lokasi kos-kosan terdekat disekitaran kampus universitas mulawarman dan dapat melihat fasilitas serta harga kos-kosan tersebut.

\section{METODOLOGI PENELITIAN}

\subsection{Prosedur Pengumpulan Data}

Pengumpulan data primer melalui studi literatur, wawancara, dan observasi, menganalisa kebutuhan perangkat lunak, melakukan digitasi peta dengan Arc View, tahapan pembuatan dari data spatial ke database dengan MySQL dengan meng-Generate API Maps Google selanjutnya koneksi ke database MySQL. merancang antar muka menggunakan CSS, HTML, Javascript dan PHP, melakukan pengujian program sebagai tahap akhir dalam pembuatan sistem informasi geografis pada objek lokasi tempat koskosan. Penelitian ini dilakukan di Samarinda tepatnya di lokasi sekitaran kampus Universitas Mulawarman dengan fokus penelitian menerapkan sebuah database spatial pada sistem informasi geografis menggunakan metode formula haversine dan mengimplementasikan kedalam website. Pengambilan data sekunder menggunakan metode dokumentasi untuk mendapatkan berbagai informasi mengenai lokasi tempat kost. Dalam perancangan perangkat lunak sistem informasi geografis membutuhkan data raster, vector dan non-spasial. Data raster berasal dari peta Kota Samarinda dalam format JPG. Data vektor merupakan data yang di implementasikan kedalam bentuk geometri titik, garis dan polygon [2]. Sementara data nonspasial merupakan data atribut informasi seperti data pemilik kos, alamat, fasilitas, dan harga Kost-kosan. 


\subsection{Metode Pengembangan Sistem}

Model Air Terjun (Waterfall) sering juga disebut model sekuensial linier (sequential linier) atau alur hidup klasik (classic life cycle). Model air terjun menyediakan pendekatan alur hidup perangkat lunak secara sekuensial atau terurut dimulai dari [10].

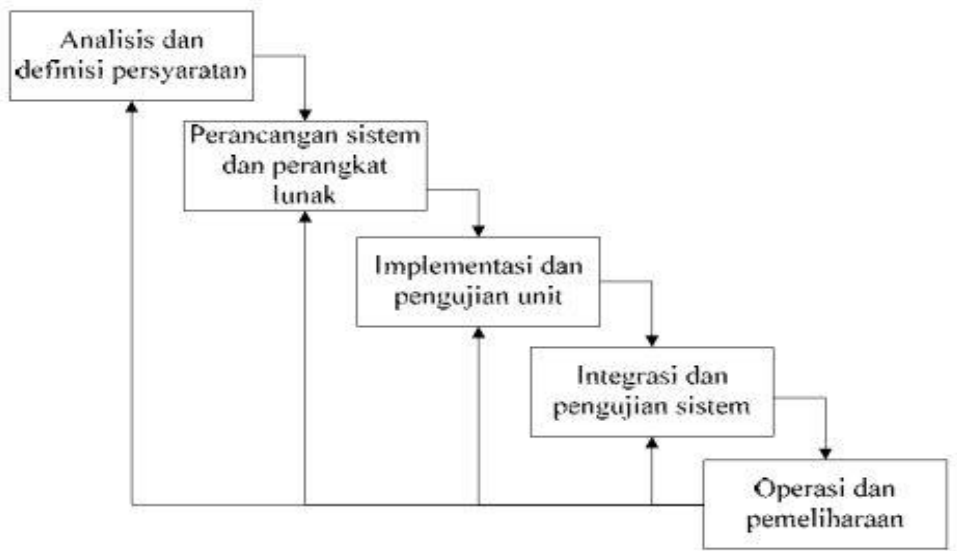

Gambar 2. Waterfall Model

\subsubsection{Tahap Analisa Kebutuhan}

Langkah ini merupakan analisis terhadap kebutuhan sistem. Pengumpulan data dalam tahap ini bisa melakukan sebuah penelitian, wawancara atau studi literature. Sistem analisis akan menggali informasi sebanyak-banyaknya dari user sehingga akan tercipta sebuah system komputer yang bisa melakukan tugas-tugas yang diinginkan oleh user tersebut. Tahapan ini akan menghasilkan dokumen user requirement atau bisa dikatakan sebagai data yang berhubungan dengan keinginana user dalam pembuatan system. Dokumen inilah yang akan menjadi acuan system analis untuk menerjemahkan kedalam bahasa pemrogram [10].

\subsubsection{Tahap Perancangan Sistem}

Tahapan dimana dilakukan penuangan pikiran dan perancangan system terhadap solusi dari permasalahan yang ada dengan menggunakan perangkat pemodelan system seperti Flowchart, dan site map serta setruktur dan bahasa data [10].

\subsubsection{Tahap Implementasi}

Penulisan kode program atau coding merupakan penerjemahan design dalam bahasa yang bisa dikenali oleh computer. Dilakukan oleh programmer yang akan meterjemahkan transaksi yang diminta oleh user. Tahapan ini lah yang tahapan secara nyata dalam mengerjakan suatu sistem. Dalam artian penggunaan computer akan dimaksimalkan dalam tahapan ini. Setelah pengkodean selesai maka akan dilakukan testing terhadap sistem yang telah 
dibuat tadi. Tujuan testing adalah menemukan kesalahan-kesalahan terhadap system tersebut dan kemudian bisa diperbaiki [10].

\subsubsection{Tahap Testing}

Tahapan akhir dimana system yang baru diuji kemampuan dan keefektifannya sehingga didapatkan kekurangan dan kelemahan system yang kemudian dilakukan pengkajian ulang dan perbaikan terhadap aplikasi menjadi lebih baik dan sempurna [10].

\subsubsection{Tahap Maintenance}

Perangkat lunak yang sudah disampaikan kepada pelanggan pasti akan mengalami perubahan. Perubahan tersebut bisa karena mengalami kesalahan karena pernagkat lunak harus menyesuaikan dengan lingkungan (peripheral atau system operasi baru) atau karena pelanggan membutuhkan perkembangan fungsional [10].

a) Keuntungan Metode Waterfall

1. Kualitas dari system yang dihasilkan akan baik. Ini dikarenakan oleh pelaksanaannya secara bertahap. Sehingga tidak terfokus pada tahapan tertentu.

2. Dokumen pengembangan system sangat terorganisir, karena setiap fase harus terselesaikan dengan lengkap sebelum melangkah ek fase berikutnya. Jadi setiap fase atau tahapan akan mempunyai dokumen tertentu.

b) Kelemahan Metode Waterfall

1. Diperlukan manajemen yang baik, karena proses pengembangan tidak dapat dilakukan secara berulang sebelum terjadi suatu produk.

2. Kesalahan kecil akan menjadi masalah besar jika tidak diketahui sejak awal pengembangan. Pelanggan sulit menyatakan kebutuhan secara terperinci sehingga tidak dapat mengakomodasi ketidak pastian pada saat awal pengembangan[10]. 


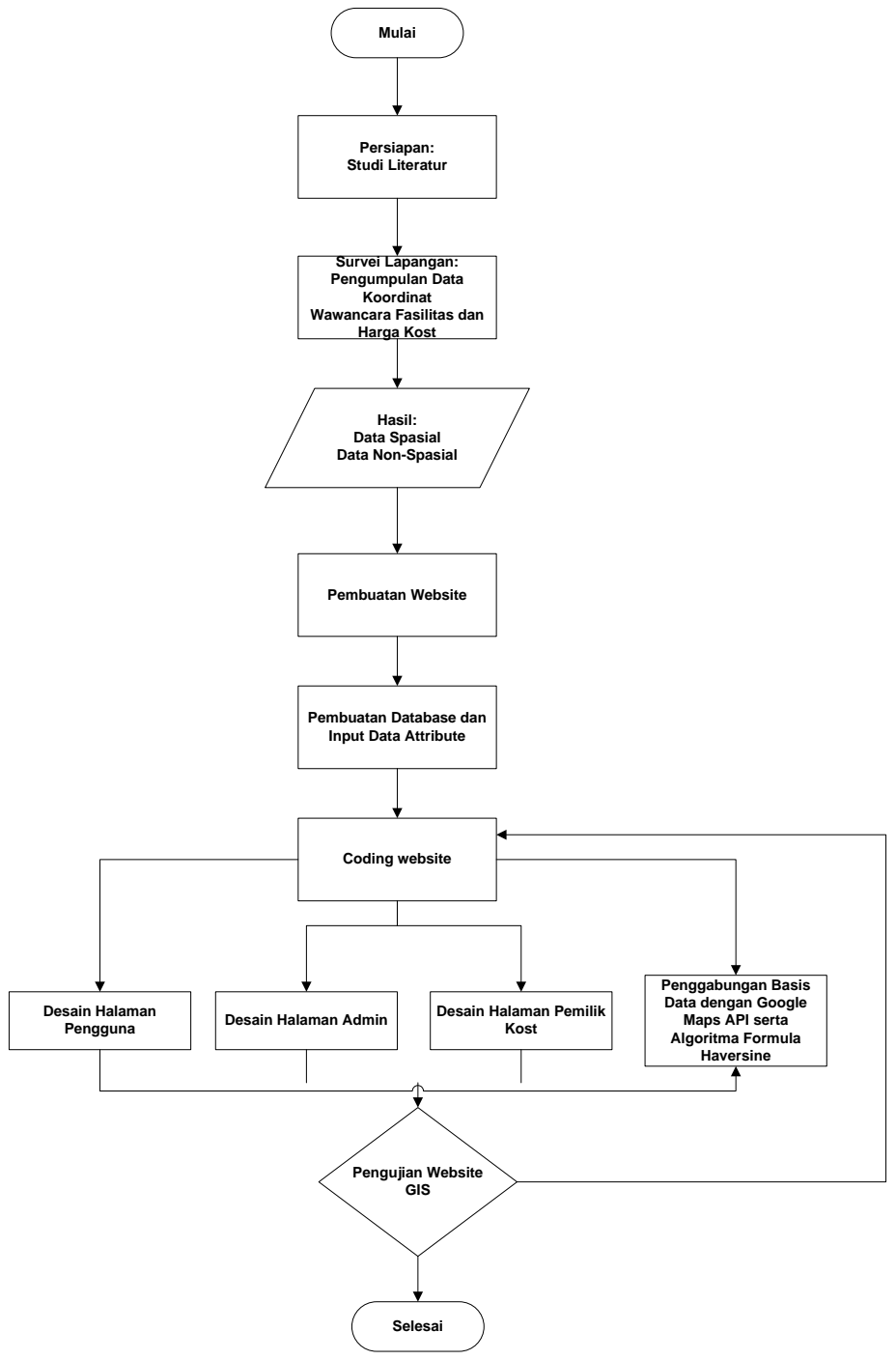

Gambar 3. Diagram Alir Penelitian

\subsection{Metode Perancangan Sistem}

Penelitian yang dilaksanakan menggunakan metode perancangan sistem yaitu (UML) Unified Modelling Language adalah sebuah patokan bahasa untuk menulis kerangka kerja secara rinci dari sebuah perangkat lunak. UML digunakan untuk memvisualisasikan, menentukan, membangun, dan mendokumentasikan sistem perangkat lunak [11]. Berikut ini adalah beberapa jenis dari diagram Unified Modelling Language (UML) [11].

\subsubsection{Use Case Diagram}

Use Case Diagram membantu menentukan fungsi dan fitur dari perangkat lunak. Dalam diagram ini, gambar yang menyerupai boneka kayu mewakili aktor yang berhubungan dengan kategori dari pengguna. Di dalam diagram Use Case, para aktor terhubung oleh garis ke Use Case yang mereka kerjakan. 


\subsubsection{Class Diagram}

Unsur-unsur utama dari diagram kelas adalah kotak, kotak tersebut merupakan ikon yang digunakan untuk mewakili kelas dan interface. kotak dibagi menjadi tiga bagian yaitu pada bagian atas berisi nama kelas, bagian tengah berisi daftar atribut kelas, dan bagian tengah bawah merupakan operation dari kelas tersebut.

\subsubsection{Activity Diagram}

Sebuah diagram activity yang menggambarkan perilaku dinamis dari sebuah sistem. Hal ini mirip dengan sebuah flowchart kecuali bahwa sebuah diagram activity dapat menunjukan arus bersamaan.

\section{HASIL DAN PEMBAHASAN}

\subsection{PERANCANGAN PERANGKAT LUNAK}

Perancangan perangkat lunak sistem informasi geografis diawali dengan tahap analisa kebutuhan dengan berdiskusi langsung dengan pihak pemilik kost-kosan untuk mendapatkan berbagai informasi mengenai keberadaan sebuah tempat kost tersebut. Berikut ini uraian dari kebutuhan dalam perancangan sistem informasi geografis pemetaan lokasi kost-kosan disekitaran kampus Universitas Mulawarman, diantaranya adalah lokasi tempat kost yang menampilkan informasi secara detail mengenai fasilitas kost, harga serta gambar keseluruhan kost-kosan dari seluruh sudut ruangan. Sistem Infromasi Geografis ini memiliki halaman khusus bagi pemilik kost untuk mengelola semua informasi mengenai tempat kostnya agar dapat memberikan informasi yang akurat sesuai kebutuhan mahasiswa atau penyewa. Pemilik kost dapat mengupdate semua informasi mengenai fasilitas kost-kosan agar pengguna atau penyewa yang dapat menentukan pilihannya secara tepat. Sistem Informasi Geografis memiliki tampilan peta pada halaman utama sehingga dapat mempermudah mengetahui lokasi tempat kost dalam bentuk peta secara digital. Memiliki fasilitas pencarian alamat tempat kost, dan menampilkan detail kost yang telah diklik [2].

Selanjutnya proses perancangan sistem yang merupakan lanjutan dari proses analisa kebutuhan. Pada tahap ini akan menghasilkan dokumen user requirement untuk kebutuhan pembuatan perangkat lunak. Dalam proses perancangan sistem informasi geografis untuk pemetaan lokasi kost-kosan disekitaran kampus Universitas Mulawarman meliputi spesifikasi perangkat keras, perangkat lunak dan metode pengembangan. Untuk perangkat keras hanya cukup memiliki GPS Global Positioning System atau hanphone yang memiliki google Maps API untuk mendapatkan informasi titik koordinat. Sedangkan untuk perangkat lunak hanya membutuhkan Windows 7, XAMPP 5.3, Texteditor, web browser, Google Maps API. Sedangkan untuk pengembangan website SIG menggunakan bahasa pemrogramman PHP, HTML, Javascript dan database MySQL, 
Rancangan tampilan peta dan informasi kost-kosan yang digunakan oleh pencari kost untuk mengetahui informasi dari setiap kost yang telah terdapat pada website aplikasi Sistem Informasi Geografis[2].

\subsection{Perancangan Data}

Sistem Informasi Geografis pemetaan kost-kosan menerapkan metode Formula Haversine dan sistem dikembangkan berbasis website agar memudahkan pengguna dalam mengakses system[12]. Sistem ini menggunakan 300 data kost yang berada sekitaran kampus Universitas Mulawarman Samarinda Kalimantan Timur.

Pencarian lokasi kos-kosan memanfaatkan GeoLocation dari GoogleMaps. Pada proses pencarian jarak dari titik koordinat pengguna dan titik koordinat kos-kosan yang telah diinput menggunakan Formula Haversine. Jarak yang didapatkan dari perhitungan Haversine kemudian dibandingkan dan dicari nilai terkecil. Nilai tersebutlah yang kemudian menjadi jarak terpendek, kemudian sistem menampilkan hasil dari perhitungan dengan visualisasi peta[12].

Google Maps API dimanfaatkan untuk menampilkan peta digital beserta rute dan arah dari titik koordinat pengguna ke titik koordinat kos-kosan terdekat. Setelah mendapatkan koordinat pengguna, kemudian siste mulai menghitung jarak menggunakan Formula Haversine[12].

\subsection{Perancangan Proses}

Pada tahapan ini melakukan perancangan proses pencarian kos-kosan terdekat menggunakan Activity Diagram. Pengguna sitem menjalankan aktivitas pencarian dengan menekan tombol search kemudian menginputkan lokasi terdekat, secara otomatis system akan membaca dan melakukan proses perhitungan jarak dengan Algoritma Formula Haversine dan melakukan proses pencarian lokasi. System akan menampilkan hasil dalam bentuk peta digital dan pengguna mendapatkan hasil lokasi kos-kosan terdekat. 


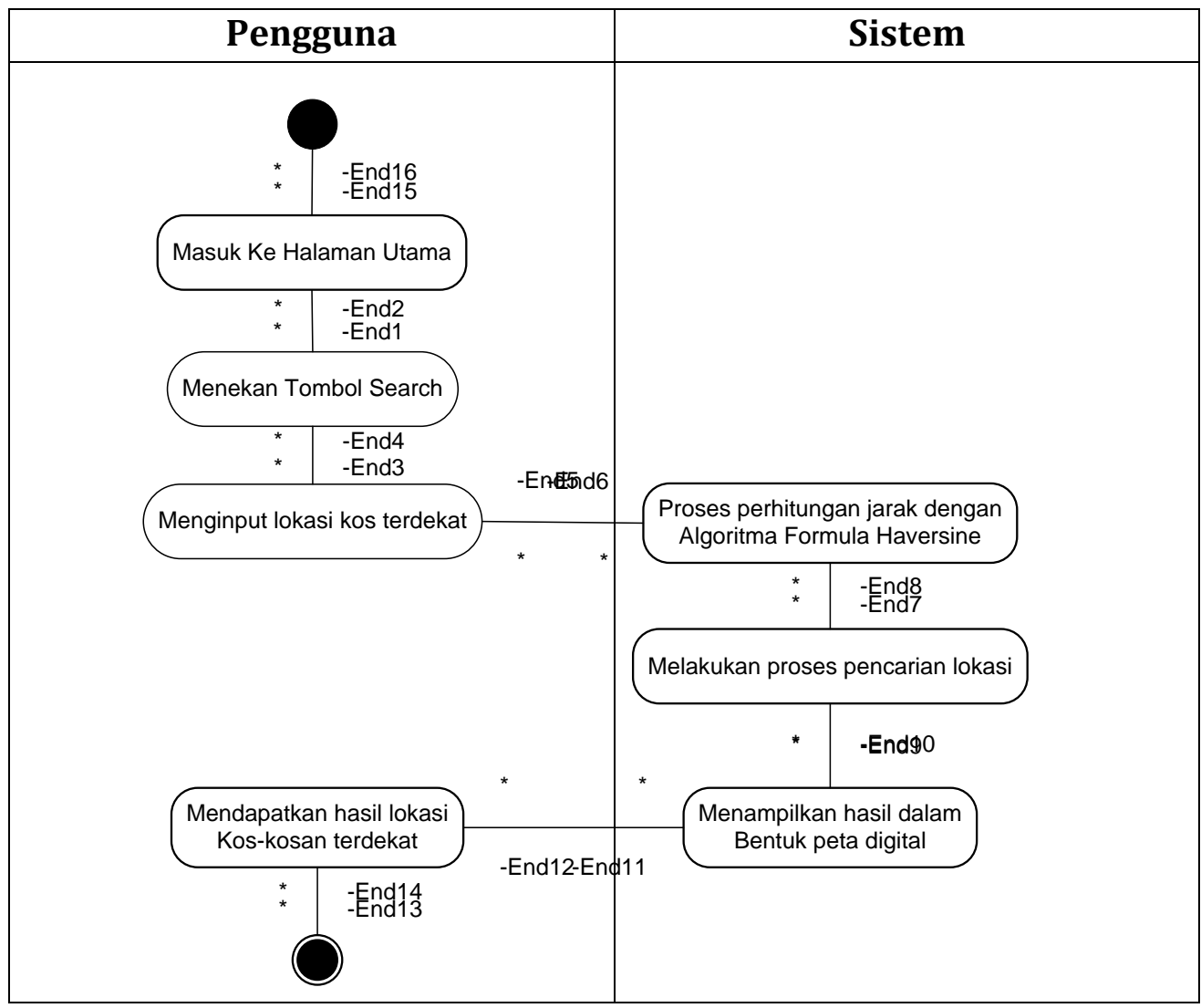

Gambar 4. Perancangan Proses

\subsection{Halaman Pemilik Kost}

Hasil rancangan form menu pemilik kost-kosan dipergunakan oleh pemilik kost untuk melakukan perubahan data pemilik, pengisian data kost dan untuk melihat daftar penyewa yang telah melakukan penyewaan terhadap kost tersebut. Berikut gambar halaman pemilik kost.

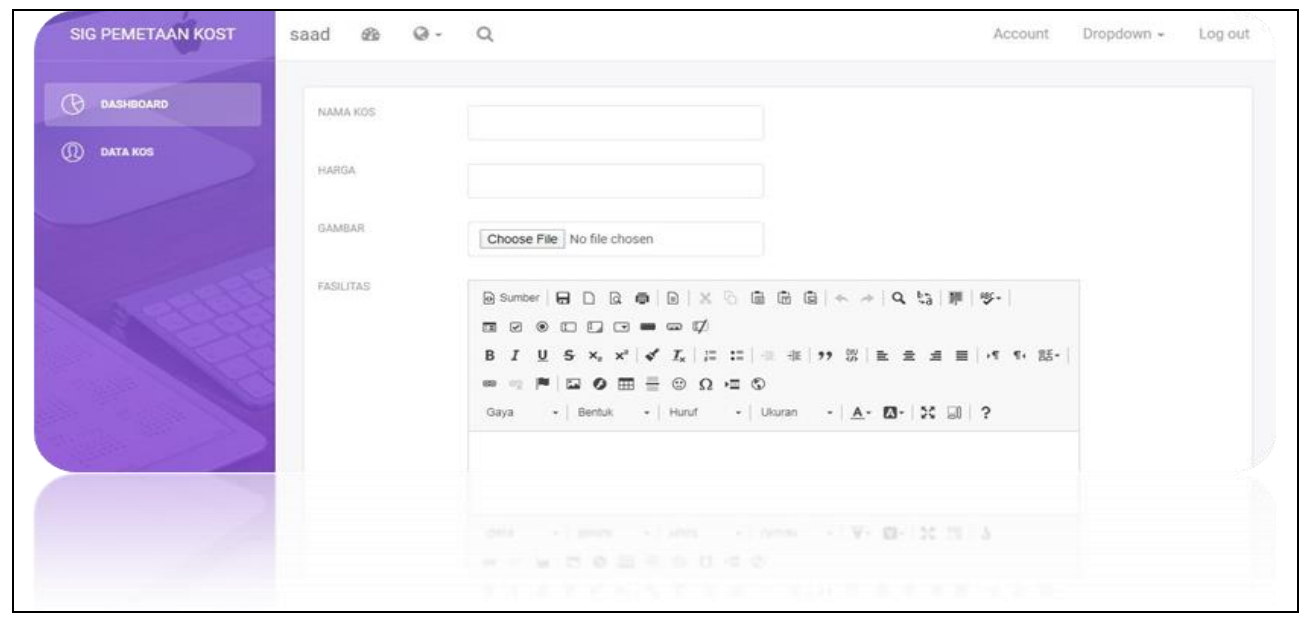

Gambar 5. Halaman Pemilik Kost 


\subsection{Halaman Admin}

Sedangkan hasil rancangan tampilan halaman admin digunakan oleh super admin untuk bertanggungjawab penuh secara teknis terhadap jalannya aplikasi. Berikut tampilan halaman admin.

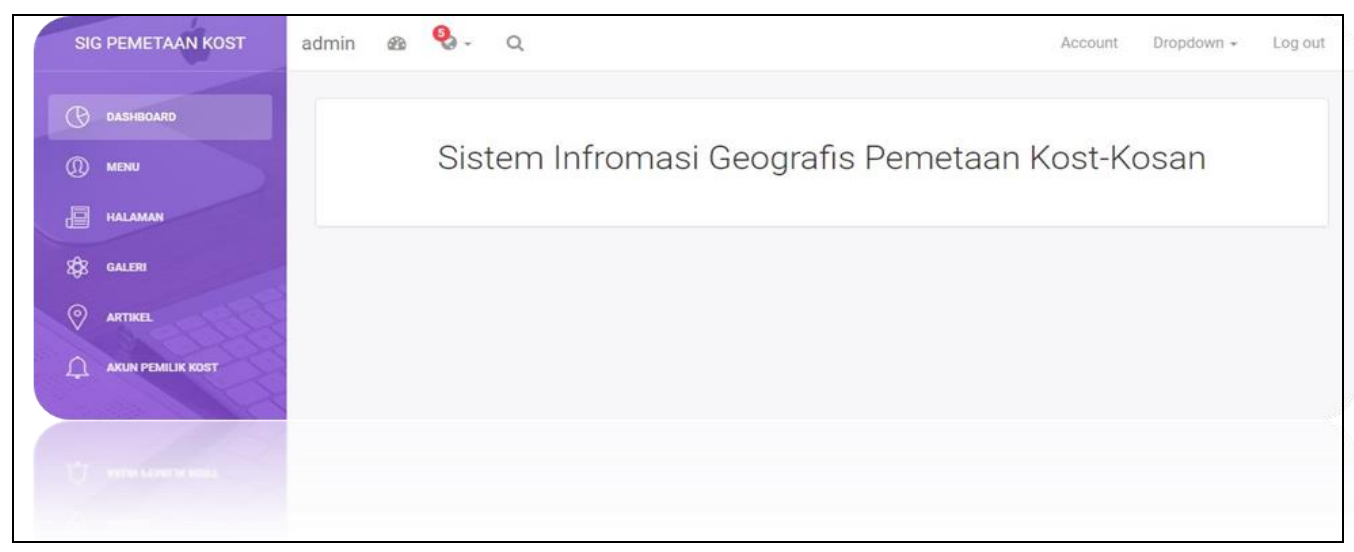

Gambar 6. Halaman Admin

\subsection{Halaman Google Maps Pengguna}

Pada halaman pengguna terdapat peta dasar Google Maps API yang menyajikan persebaran lokasi kost terdekat disekitaran lingkungan kampus Universitas Mulawarman. Berikut gambar halaman Google Maps.

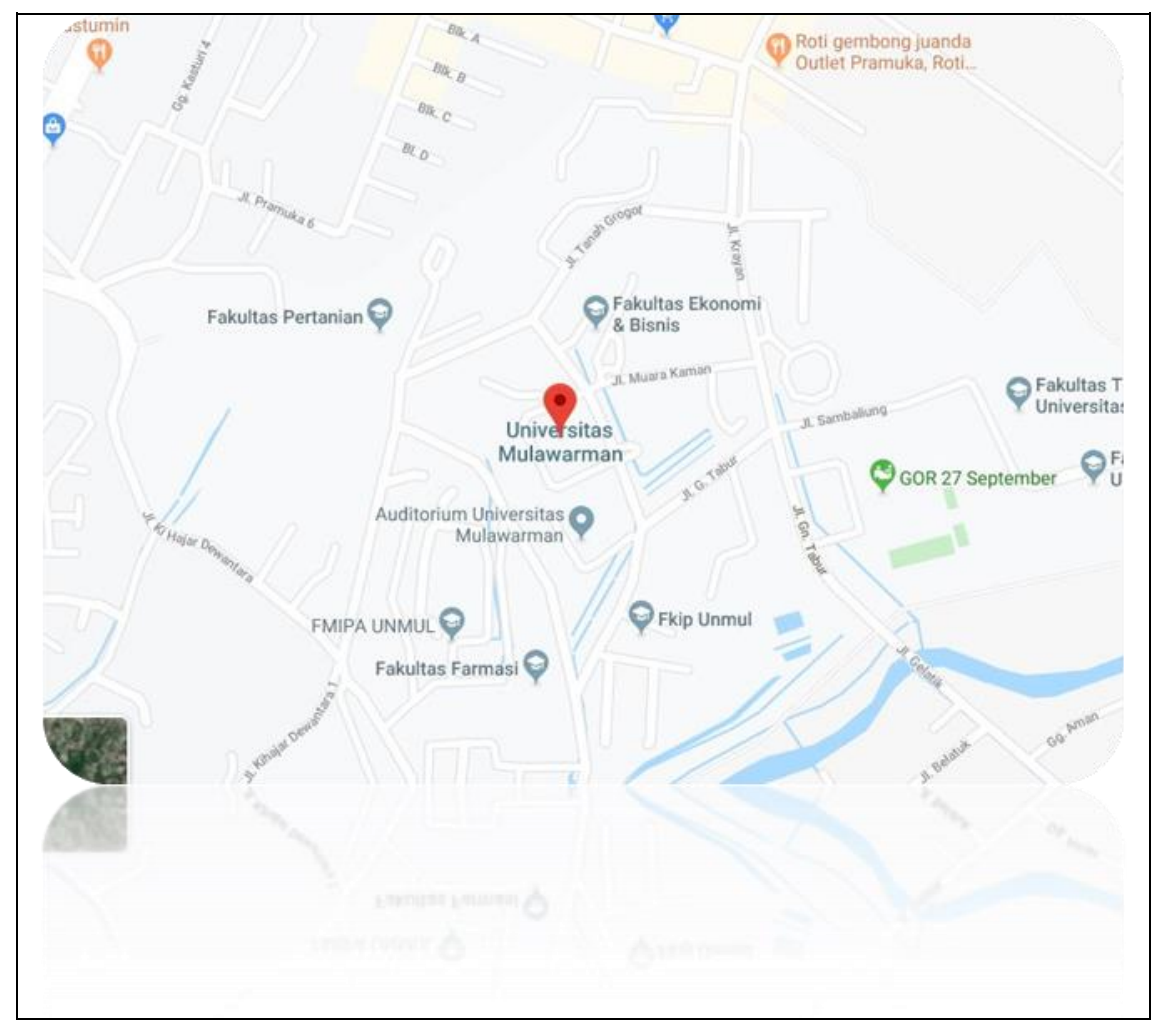

Gambar 7. Halaman Google Maps 


\section{SIMPULAN}

Dengan menerapkan database spatial Sistem Informasi Geografis serta penggunaan Algoritma Formula Haversine, maka kesimpulan yang dapat diambil adalah:

a) Telah dihasilkan peta penyebaran lokasi kos-kosan disekitar kampus universitas mulawarman dengan informasi jarak terpendek antara titik lokasi kos dan lokasi pengguna.

b) Sistem mampu menghasilkan pemetaan lokasi kos-kosan serta dilengkapi dengan informasi keseluruhan mengenai kos tersebut.

c) Penerapan algoritma Formula Haversine mampu memberikan informasi jarak terpendek antara pengguna dan kos-kosan.

\section{DAFTAR PUSTAKA}

[1] B. E. Tjahjana, N. Heryana, dan N. A. Wibowo. 2015. Penggunaan Sistem Informasi Geografis (SIG) Dalam Pengembangan Kebun Percobaan, Sirinov, vol. 3, no. 2, pp. 103-112.

[2] Sandi Kosasi, 2014, Sistem Informasi Geografis Pemetaan Tempat Kost Berbasis Web. CSRID Journal, Vol.6 No.3, Hal. 171-181.

[3] Soenarmo, Sri Hartati, 2009, Penginderaan jauh dan pengenalan Sistem Informasi Geografis untuk bidang Ilmu Kebumian. ITB Bandung.

[4] Soenarmo, Sri Hartati, 2009, Penginderaan jauh dan pengenalan Sistem Informasi Geografis untuk bidang Ilmu Kebumian. ITB Bandung.

[5] Qolis, N, 2010, Pemetaan dan Analisa sebaran sekolah untuk peningkatan layanan pendidikan di Kabupaten Kediri dengan GIS. Diakses http://www.eepisits.edu/uploadta/downloadmk.php?id=912.

[6] Sunil Pratap Singh and Preetvanti Singh, 2014, Modeling A Geo-Spatial Database For Managing Traveler's Demand. International Journal of Database Management System (IJDMS), Vol.6, No.2.

[7] ZHAO Chun-yu, ZHAO Yuan-chun, MENG Ling-kui, DENG Shi-jun, 2019, The Key Technologic Issues of Parallel Spatial Database Management System For Parallel GIS. The School of Remote Sensing and Information Engineering, Wuhan University, Wuhan, China -zcy7@263.net.

[8] H. A. Umar , M. F. Abdul Khanan , ${ }^{*}$ A. Ahmad M. J. Sani , M.Z. Abd. Rahman ,A. Abdul Rahman, 2019, Spatial Database Development For Oil Spills Pollution Affecting Water Quality System in Niger Delta. The International Archives of the Photogrammetry, Remote Sensing and Spatial Information Sciences, Volume XLII-4/W16, 2019 6th International Conference on Geomatics and Geospatial Technology (GGT 2019), Kuala Lumpur, Malaysia.

[9] Sugiarto, Ertien Rining Nawangsari, 2019, Data Spatial Pada Pembuatan Peta Tematik Dengan API Maps Google. ISBN : 978-6-02-526748-2 - SEMINAR SANTIKA.

[10] SimarmataJaner, 2009, Rekayasa Web, Yogyakarta:Andi

[11] Pressman, Roger S. 2010. Software Engineering : A Practicioner's Approach, 7th Edition. McGraw-Hill Inc : New York

[12] Yulianto, Ramadiani, Awang, 2018. Penerapan Formula Haversine Pada Sistem Informasi Geografis Pencarian Jarak Terdekat Lokasi Lapangan Futsal. Informatika Mulawarman : Jurnal Ilmiah Ilmu Komputer, e-ISSN 2597-4963 dan p-ISSN 1858-4853. 